\title{
EXCLUSÃO DIGITAL
}

\section{Problemas conceituais, evidências empíricas e políticas públicas'}

\author{
BERNARDO SORJ \\ LUÍS EDUARDO GUEDES
}

\section{RESUMO}

Partindo de uma pesquisa realizada nas comunidades de baixa renda do município do Rio de Janeiro, este artigo pretende contribuir para a compreensão da dinâmica de inclusão e exclusão digital nos setores mais pobres da população. Com base numa amostragem que representa um universo de cerca de 1,2 milhão de pessoas, procura ir além da polaridade entre os que têm e os que não têm acesso a computador e Internet enfatizando os múltiplos aspectos da exclusão digital e apresentando suas implicações para a elaboração de políticas públicas e projetos sociais.

PALAVRAS-CHAVE:Internet; exclusão digital; exclusãosocial.

\section{SUMMARY}

Starting from a survey held in poor communities of the city of Rio de Janeiro, this article tries to make a contribution at the understanding of the dynamics of digital inclusion and exclusion in the poorest sectors of population. Starting from a sampling that represents around one million and two hundred thousand people, this work tries to go beyond the polarity between those who have means to access computers and internet and those who don't, emphasizing the multiple aspects of digital exclusion and presenting its implications to the making of public policies and social projects.

KEYWORDS: Internet; digitalexclusion; socialexclusion.

[1] Agradecemos ao ICA (Institute for Connectivy Americas)/IDRC e à Unesco o apoio para a realização da pesquisa. Este trabalho não teria sido possível sem os comentários de Rubem César Fernandes, Franklin Coelho e sem a dedicação da equipe do Núcleo de Pesquisas Favela, Opinião e Mercado do ISER/Viva Rio

[2] No primeiro survey, foi realizado um levantamento com um universo representativo do conjunto dos ha-
Este artigo procura contribuir para a compreensão da dinâmica de inclusão e exclusão digitais nos setores mais pobres da população com base nos resultados de uma pesquisa quantitativa e qualitativa realizada nas comunidades de baixa renda do município do Rio de Janeiro. O survey foi executado em duas etapas ${ }^{2}$ no segundo semestre de 2003, cada uma das quais com 1.500 entrevistas, o que representa um universo de cerca de 1,2 milhão de pessoas. A pesquisa foi complementada com reuniões de oito grupos focais, com amostras de várias faixas etárias e de gênero. 
bitantes das favelas. No segundo foram pesquisadas seis favelas, duas com renda média mais alta, duas de renda média intermediária e uma de renda média baixa, utilizando-se um questionário mais detalhado. Enquanto no primeiro survey foi incluída a população acima de 15 anos que utiliza ou não microcomputadores, no segundo foram incluídas crianças a partir de 10 anos, e todos os entrevistados deveriam fazer uso do microcomputador, de forma a aprofundar o conhecimento desse universo.

[3]Cf. Bernardo Sorj, brasil@povo.com. A luta contra a desigualdade na sociedade da informação, Rio de Janeiro: Jorge Zahar, 2003.

[4] Uma bibliografia sobre a exclusão digital disponível na Internet pode ser encontrada em Sorj, B., e-biblo-graphy on digital divide". Disponível em: 〈http:/www.bernardosorj.com.br/pdf/ e bilbiografiaexclusaodigital.pdf $>$.
[5] Reproduz-se uma oposição bastante comum entre estudos quantitativos, realizados geralmente por economistas, e trabalhos qualitativos, realizados por sociólogos e antropólogos. 
[6] Isto é, a análise das conseqüências sociais, econômicas e culturais da distribuição desigual do acesso às novas tecnologias da informática e comunicação.

[7] Como o faz, por exemplo, o Mapa da Exclusão Digital da Fundação Getulio Vargas: Disponivel em: 〈http:// www 2.fgv.br/ibre/cps/mapa_exclusao/apresentacao/apresentacao.htm>
Os estudos estatísticos ${ }^{6}$, em particular sobre os países em desenvolvimento, por sua vez, adotam como parâmetro central, e em geral único, a divisão entre os que têm e os que não têm acesso à informática e à Internet no lar. Embora importante, essa medida é insuficiente para a compreensão da dinâmica social da exclusão digital e a definição de políticas de universalização de acesso por apresentar três grandes limitações: não identificar a qualidade do acesso - velocidade da conexão, custo e tempo disponível para ele -, em particular nos grupos mais pobres da população; supor o universo de usuários entre os que possuem computador no domicílio na diferenciação das camadas socioeconômicas; não oferecer pistas sobre a diversidade de usos e a relevância da inclusão digital para os usuários (aspecto que, embora central, não será abordado aqui). A exclusão digital não se refere a um fenômeno simples, limitado ao universo dos incluídos e excluídos, polaridade real mas que por vezes mascara seus múltiplos aspectos. A razão é simples: a oposição entre acesso e não acesso é uma generalização razoável quando se trata de serviços públicos ou de bens tradicionais de consumo intermediário. Para aferir a exclusão digital, contudo, o número de proprietários de computador ou de pessoas com acesso à Internet é uma medida primitiva demais, já que vários outros fatores devem ser considerados: o tempo disponível e a qualidade do acesso afetam decisivamente o uso da Internet; as tecnologias da informação e comunicação (daqui em diante usaremos o termo telemática) são muito dinâmicas e requerem constantes atualizações de hardwares, softwares e dos sistemas de acesso, que exigem um investimento regular por parte do usuário para não ficarem obsoletos; seu potencial de utilização depende da capacidade de leitura e interpretação da informação pelo usuário (no caso da Internet) e por sua rede social (no caso do e-mail).

Apresentaremos alguns dos principais resultados da pesquisa $e$ suas implicações para a elaboração de políticas e projetos sociais. Devemos destacar que enfatizamos aqui a inclusão digital dos indivíduos. Outros aspectos também deverão ser considerados: em certos contextos a inclusão digital de instituições comunitárias pode melhorar a qualidade de vida das populações pobres, em particular daquelas espacialmente isoladas, oferecendo serviços e informações de valor cultural, econômico e social.

\section{UNIVERSO DE USUÁRIOS}

A inclusão digital é geralmente definida num país pela relação entre a porcentagem de pessoas com acesso a computador e/ou Internet no domicílio e o total da população ${ }^{7}$. Para identificar as pessoas incluídas, o critério geralmente utilizado é o número de computadores por domicílio e/ou de computadores por domicílio com acesso à Internet. Essa metodologia já foi alvo de críticas, pois em países com 
um número significativo de pontos de acesso coletivo (comumente denominados telecentros ou cibercafés) o número de pessoas que acessam a Internet por computador é muito maior que a média de acesso por domicílio. Argumenta-se também que as famílias de classe média normalmente possuem mais de um computador por domicílio, fato que não ocorre nas famílias pobres, o que significaria um número maior de usuários por computador nas famílias pobres e menor nas famílias de classe média.

No caso brasileiro, o impacto estatístico dos telecentros é secundário, dado que seu número em escala nacional ainda é relativamente pequeno, embora, como veremos, esteja longe de ser insignificante para as comunidades onde se localizam. Por sua vez, a expectativa de um maior número de usuários por computador no domicílio das famílias pobres deve ser qualificada, já que, como indica a pesquisa, na maioria dos casos são poucos os seus membros que usam computador.

Como mostram os dados a seguir, a quantificação da inclusão digital com base no número de computadores por domicílio produz uma visão totalmente errônea sobre o acesso à informática e à Internet dos setores mais pobres da população. Isso porque somente a metade dos que possuem computador tem acesso à Internet no domicílio e sobretudo porque, para os usuários das favelas, o local de trabalho e a casa de terceiros constituem o principal lugar de acesso.

\section{GRÁFICO I}

Posse de computador no domicílio nas comunidades do município do Rio de Janeiro

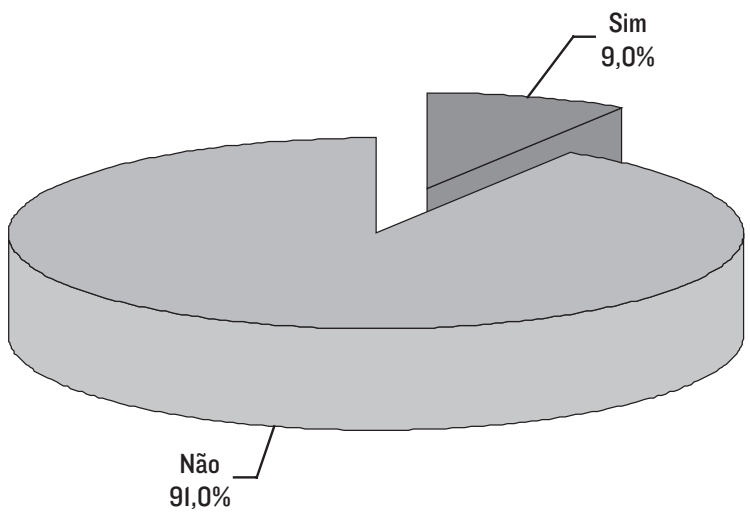

De acordo com a pesquisa, 9\% dos domicílios localizados nas favelas possuem computador. Os entrevistados e as entrevistas dos grupos focais indicaram que ele geralmente é visto como um bem de consumo pessoal, embora sua posse e sua propriedade não fiquem claramente definidas. Muitos, em particular os jovens, definem o computador como "seus", apesar de adquirido pelos pais. A questão da posse está associada diretamente à utilização, pois em geral é o usuário quem define o equipamento como seu. A tendência de se individua- 
lizar a propriedade está associada tanto ao fato de que muitos membros da família não usam computador como à vontade de afirmar a posse, dado o conflito sobre horários de utilização, tema que foi indicado nos grupos focais como produtor de tensões na família.

$\mathrm{O}$ acesso à informática nas favelas é até superior à média de muitas capitais do Norte e do Nordeste do país. Se a posse de computador nas favelas do Rio de Janeiro está próxima da média nacional, ela é 30\% inferior à média do Estado e apresenta, em referência a seu ambiente direto, o município do Rio de Janeiro, uma relação de 1 computador para 2.6 computadores (e comparados com os bairros mais ricos, a distância é em torno de 1 para 6).

GRÁFICO 2

Comparação entre as taxas de inclusão digital das comunidades de baixa renda do município do Rio de Janeiro e algumas capitais

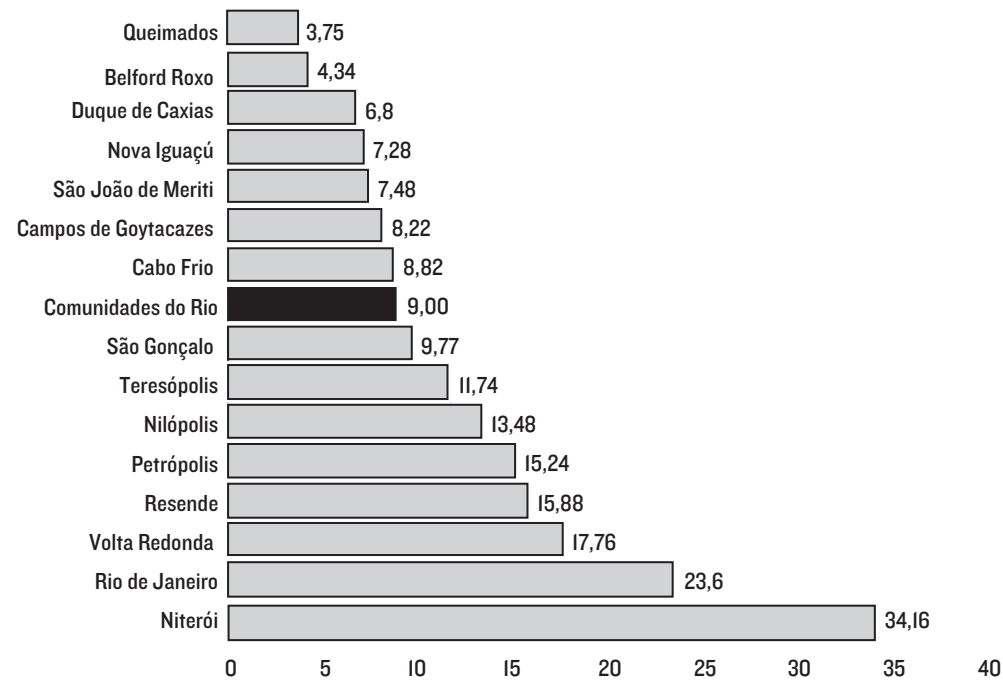

Nota: A inclusão digital, neste caso, refere-se à porcentagem de computadores no total de domicílios.

O processo desigual de disseminação do computador entre a população das diferentes cidades do Brasil reflete sem dúvida o nível desigual de riqueza e escolaridade entre as diferentes regiões e cidades, em particular entre as populações pobres das regiões Norte e Nordeste e do Centro-Sul. A posse do computador, porém, está também associada a um componente intangível: a disseminação de uma cultura de valorização da informática associada em especial à noção de que seu domínio é condição de emprego e sucesso na educação. Em outras palavras, à medida que o sistema produtivo se informatiza, a noção de que é necessário dominar esse instrumento para assegurar maiores chances de trabalho se "infiltra" rapidamente entre os diversos setores sociais, uma vez que seu uso passa a ser visto como condição para a obtenção de trabalho e sucesso escolar. De fato, a única pergunta para a qual encontramos uma resposta consensual, independentemente de grau de 
escolaridade, renda, cor e gênero, foi quanto à importância do conhecimento de informática para a obtenção de emprego: a quase totalidade dos entrevistados indicou que ele ajuda a conseguir trabalho. Portanto, se a disseminação do computador tem uma óbvia correlação com o nível de renda e de escolaridade, ela está igualmente associada aos padrões culturais mais amplos de informatização da sociedade.

A exclusão digital se dá também no interior dos grupos pobres, entre gêneros, raças e grupos etários, e entre diferentes comunidades. A menção aos bairros pobres pode dar uma falsa visão de homogeneidade, quando tanto no interior de cada um como entre eles a desigualdade em relação à posse de computador é muito pronunciada.

\section{GRÁFICO 3}

Comparação entre as taxas de inclusão digital em comunidades de baixa renda do município do Rio de Janeiro e de alguns municípios do Estado

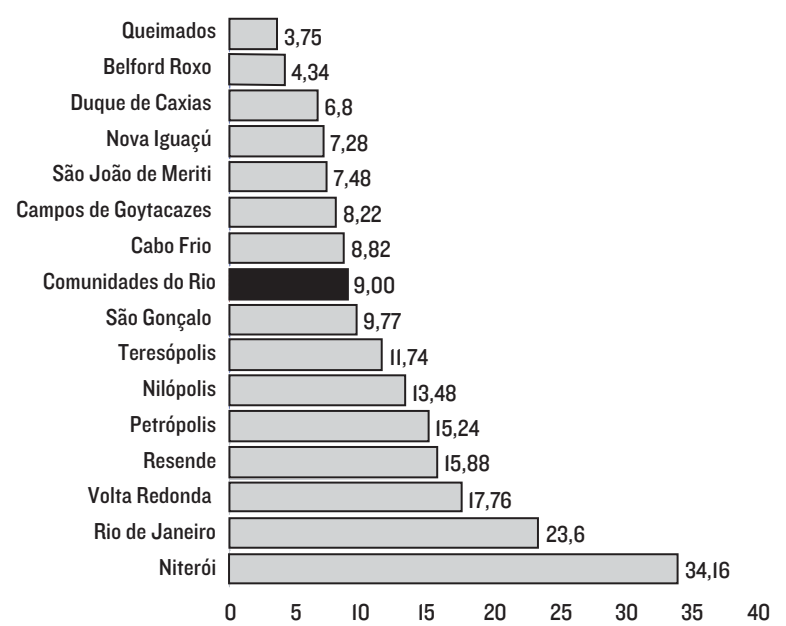

Nota: a inclusão digital, neste caso, refere-se à porcentagem de domicílios com computador.

O número de pessoas com computador no domicílio não define, todavia, o número de usuários, que chega a ser o dobro.

\section{GRÁFICO 4}

Percentual de pessoas que possuem e que utilizam microcomputadores nas comunidades de baixa renda do município do Rio de Janeiro

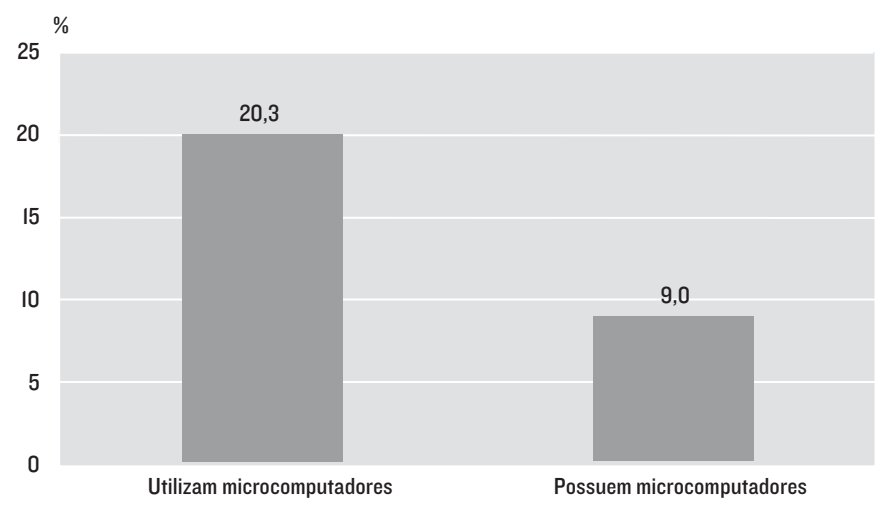


Uma explicação possível para isso seria de que cada computador é utilizado por vários membros da família. Esse argumento contudo é insuficiente, pois somente $27,6 \%$ dos entrevistados indicaram o domicílio como principal local de uso. O número maior de usuários em relação ao de proprietários advém especialmente do fato de o domicílio não ser o principal local de acesso ao computador nas favelas.

GRÁFICO 5

Principal local de utilização do microcomputador nas comunidades de baixa renda do município do Rio de Janeiro

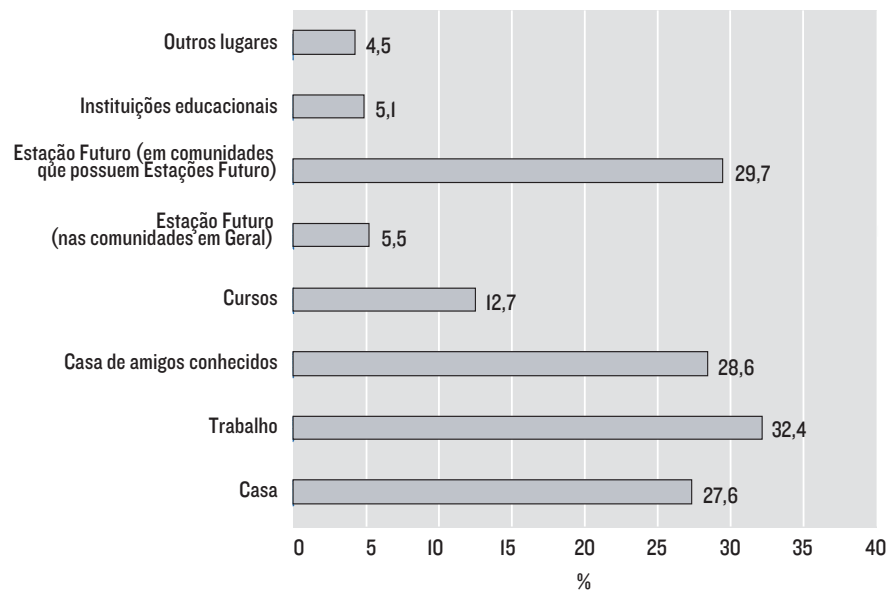

O trabalho representa o principal local de utilização do computador para os habitantes da favela, seguido da casa de amigos e conhecidos, ficando o domicílio em terceiro lugar. Nas favelas onde existem as Estações Futuro (telecentros) da ONG Viva Rio, estas ficam em segundo lugar Os dados contradizem a expectativa de que nos setores mais pobres da população o número de usuários por computador no domicílio seja alto, pois em geral são poucos os membros da família que o utilizam - geralmente dependentes e menores de idade.

GRÁFICO 6

Percentual de pessoas que possuem e utilizam microcomputadores e Internet nas comunidades de baixa renda do município do Rio de Janeiro

- Posse Utilização

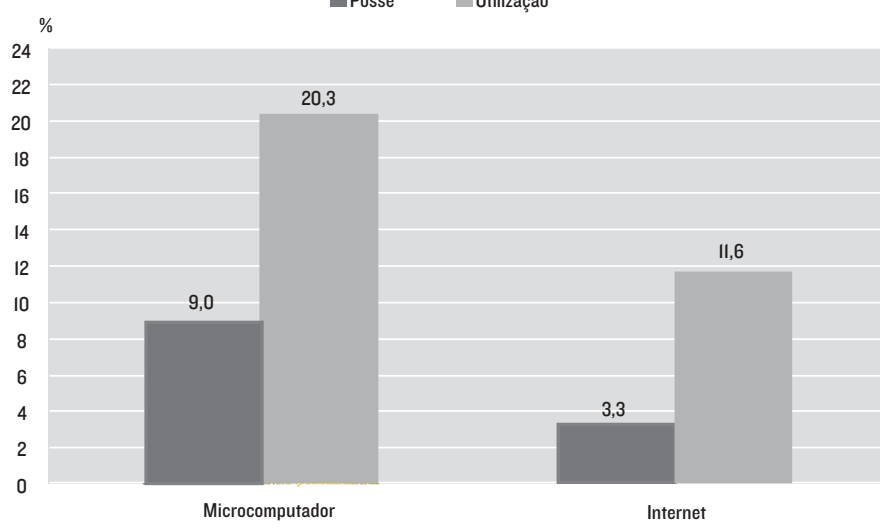

Nota: Os percentuais se referem ao total da amostra. 
O fenômeno da dissociação entre posse e usuários se reproduz em relação à Internet. Embora somente a metade dos que possuem computador em casa tenham acesso a ela, o número de usuários é mais que o triplo do que os que têm acesso no domicílio.

FATORES DE INTEGRAÇÃOE EXCLUSÃO Tanto entre os usuários existentes nas favelas, como entre a população em geral, verifica-se uma tendência decrescente do uso da informática à medida que a faixa etária aumenta. $\mathrm{Na}$ favela essa tendência é ainda mais acentuada tendo em vista os níveis de escolaridade mais baixos entre os mais idosos e as menores chances de aprendizagem no emprego.

\section{GRÁFICO 7}

Percentual de utilização do microcomputador, segundo a faixa etária

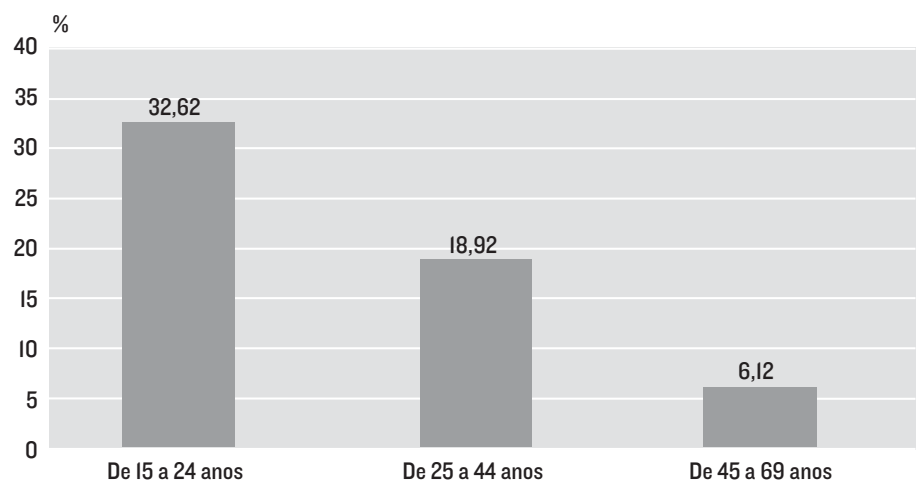

Nota: Os percentuais foram calculados em relação ao próprio grupo.

Como era de se esperar, os gráficos a seguir indicam que existe uma clara correlação entre nível de renda, escolaridade e posse de computador. O nível escolar é fundamental: entre os que possuem de 1 a 3 anos de estudos, encontramos dois computadores para cada 100 domicílios, e na faixa de pessoas com mais de 15 anos de estudo essa proporção chega a 48,9 para cada 100.

\section{GRÁFICO 8}

Renda pessoal e familiar per capita média segundo a posse de microcomputador nas favelas do município do Rio de Janeiro

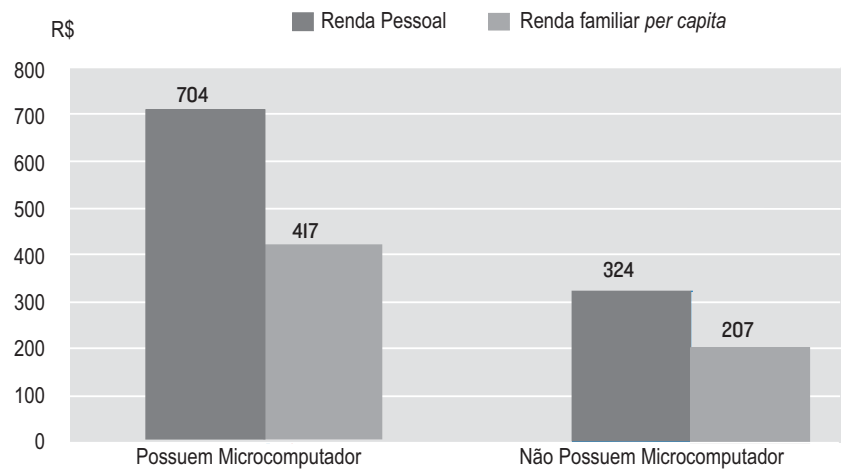


GRÁFICO 9

Percentual de pessoas que possuem computador no domicílio por faixa de anos de estudo nas favelas do município do Rio de Janeiro

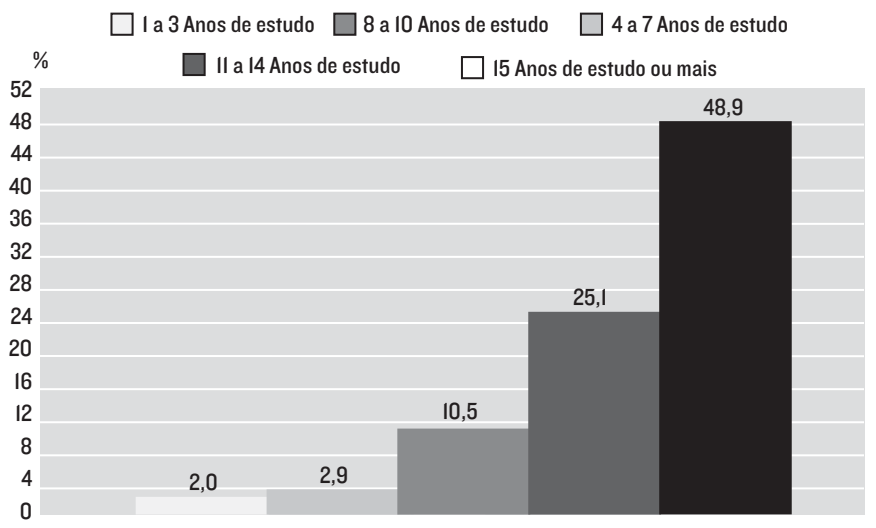

O fato de ser o local de trabalho, e não o domicílio, a principal base de acesso (e de aprendizagem e motivação de uso) ao computador e à Internet não somente muda de forma relevante o número de pessoas digitalmente incluídas, como transforma o perfil do usuário.

Como veremos a seguir, as mulheres, pelo tipo de trabalho que realizam - em geral empregadas domésticas ou em serviços de limpeza -, são as mais prejudicadas e apresentam um nível de exclusão digital muito mais elevado que os homens nas camadas pobres da população. Por outro lado, a população negra masculina, cuja média de posse de computador por domicílio é bastante inferior à da população branca da favela, encontra no trabalho um mecanismo de equiparação social. Assim, o acesso fora do domicílio tem um impacto

\section{GRÁFICO 10}

Percentual de pessoas que possuem e utilizam microcomputador por faixa de anos de estudo nas comunidades do município do Rio de Janeiro

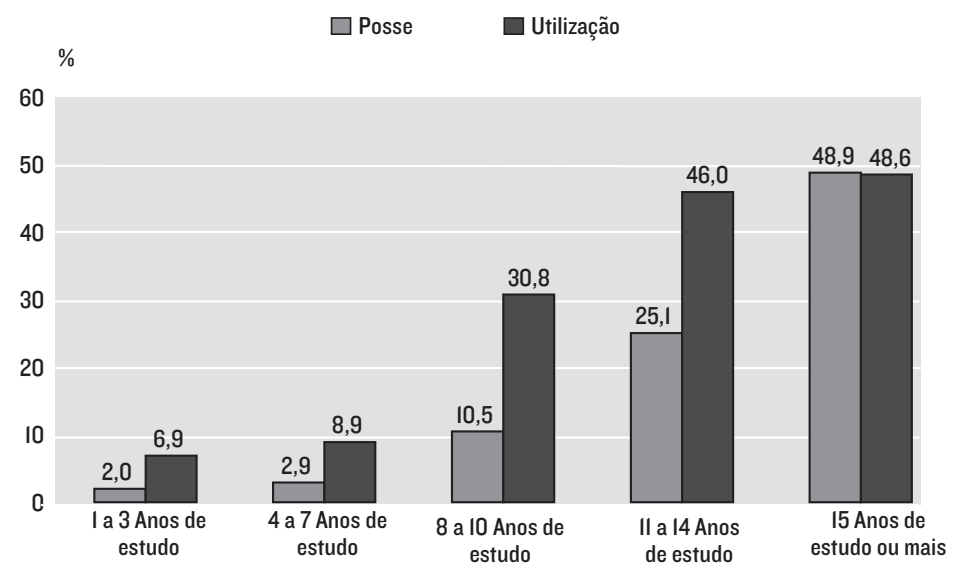

Nota: Os percentuais foram calculados em relação ao próprio grupo. 
geral democratizante, ainda que desigual, permitindo o ingresso de pessoas com renda média e nível de escolaridade mais baixo no mundo da informática.

Entre os usuários de computador dentro ou fora do domicílio o padrão que associa a renda com o uso da informática se mantém, mas a distância tende a diminuir, o que indica que as pessoas de menor escolaridade encontram nos computadores fora do domicílio um mecanismo de igualação social.

O mesmo vale para o nível de renda:

\section{GRÁFICO II}

Renda familiar per capita segundo a posse e utilização de microcomputador

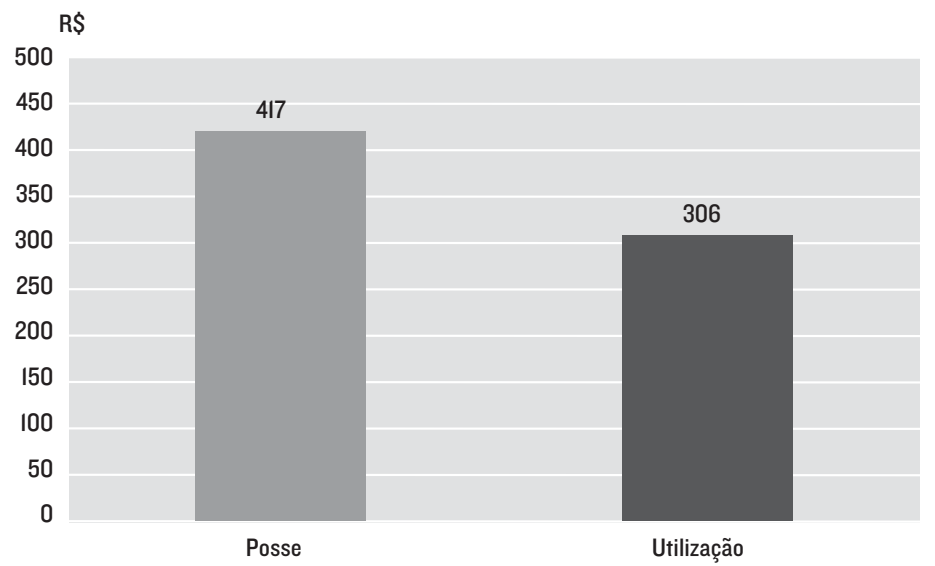

Como mostra o Gráfico 12, enquanto o percentual de pessoas brancas com posse de computador supera a média (9.0\%), e o de pardos iguala-se a ela, a população negra apresenta um nível equivalente à metade da média.

\section{GRÁFICO 12}

Percentual de pessoas que possuem computador em seu domicílio por cor/raça nas comunidades do município do Rio de Janeiro

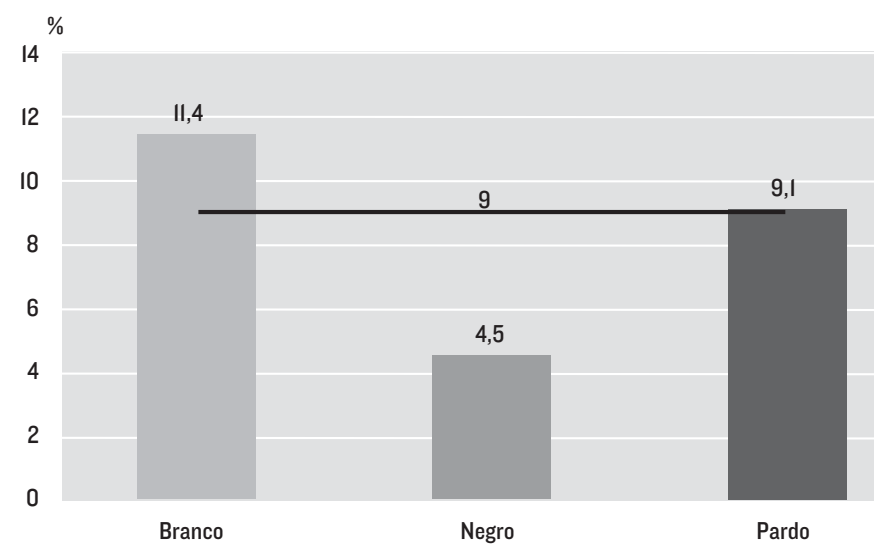

Nota: Os percentuais foram calculados em relação ao próprio grupo. 
Como indica o Gráfico 13, essa situação reflete a dupla posição desfavorecida da população negra em termos de renda e educação.

\section{GRÁFICO I3}

Comparação das médias de renda familiar per capita e anos de estudo

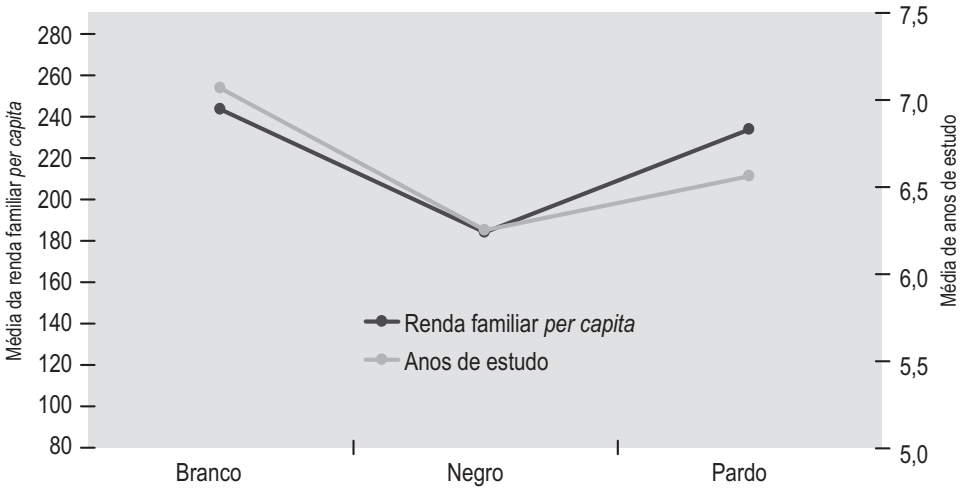

Mas em termos de usuários de informática, essa diferença tende a diminuir graças a outros acessos fora do domicílio.

\section{GRÁFICO 14}

Percentuais de posse e utilização de microcomputador, segundo cor/raça

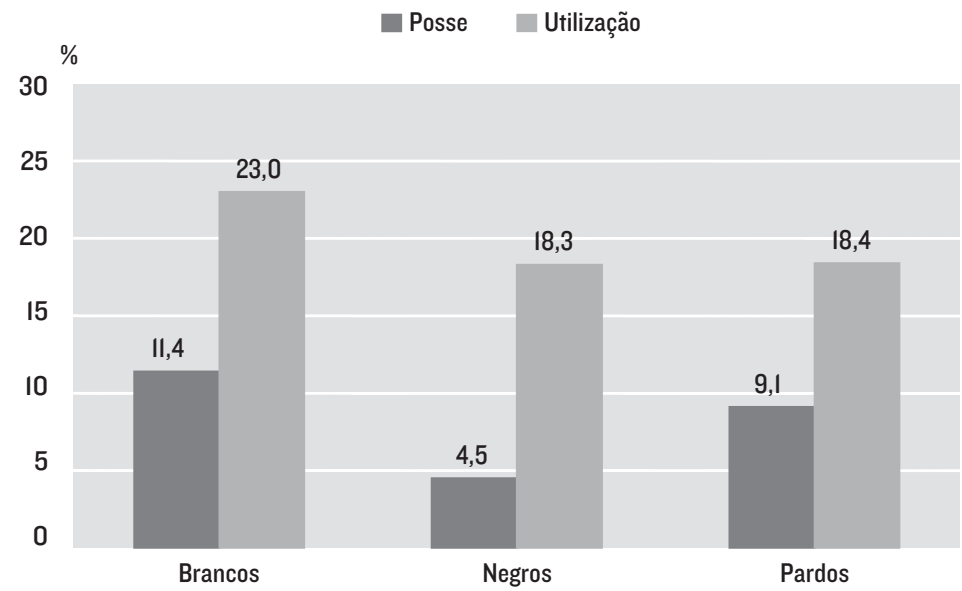

Nota 1: Os percentuais foram calculados em relação ao próprio grupo.

Nota 2: Para a utilização foi usado o universo dos que utilizam o computador (20,3\% da população).

Ou seja, o acesso fora de domicílio funciona como um fator de criação de oportunidades para a população negra. O oposto acontece com a população feminina: 


\section{GRÁFICO 15}

Utilização de microcomputadores segundo 0

sexo nas comunidades do município do Rio de Janeiro

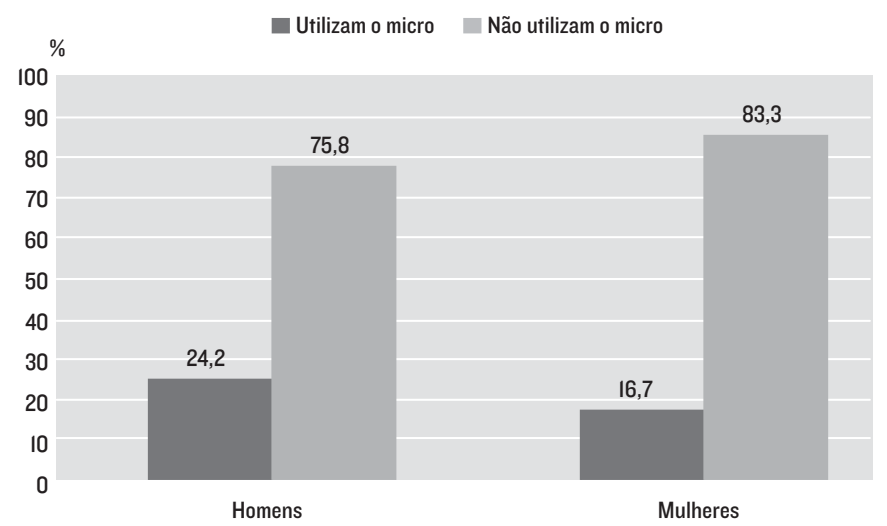

O que acontece em ambos os casos (baixo acesso das mulheres e incremento do percentual da população negra de usuários). O trabalho atua como fator de exclusão digital no caso das mulheres e de igualação social no caso dos negros. A maioria das mulheres trabalha em serviços de limpeza ou como empregadas domésticas e não tem oportunidade de utilizar computador, enquanto um número maior de homens, inclusive muitos que trabalham como office boys, acaba convivendo em ambientes que incentivam e por vezes permitem o conhecimento dos usos básicos do computador.

As tendências em relação ao uso de computadores se reproduzem em relação à Internet e são até mais marcantes. Do total de possuidores de computador, somente um terço tem acesso à Internet, de forma que, do total de usuários de Internet, pouco mais de $25 \%$ o fazem no domicílio, reproduzindo os padrões de uso mencionados acima, isto é, a principal fonte de acesso se encontra fora do domicílio.

\section{GRÁFICO I6}

Locais de acesso à Internet mais utilizados nas comunidades do município do Rio de Janeiro

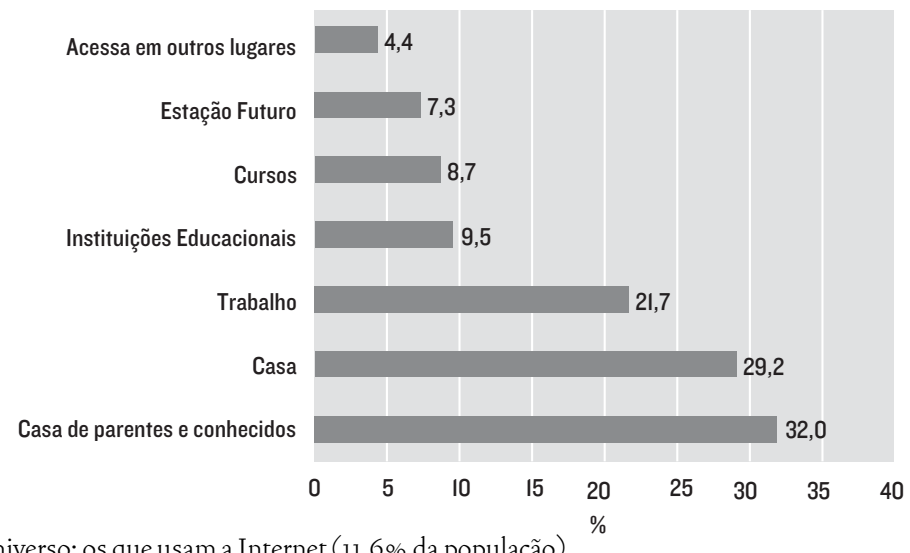

112 EXCLUSÃo diGital 【 Bernardo SorJ / Lú́s Eduardo Guedes 
No uso da Internet a faixa etária é ainda mais decisiva, já que sua importância aumenta nos setores mais jovens:

\section{GRÁFICO 17}

Percentual de utilização de Internet e computador, segundo a idade

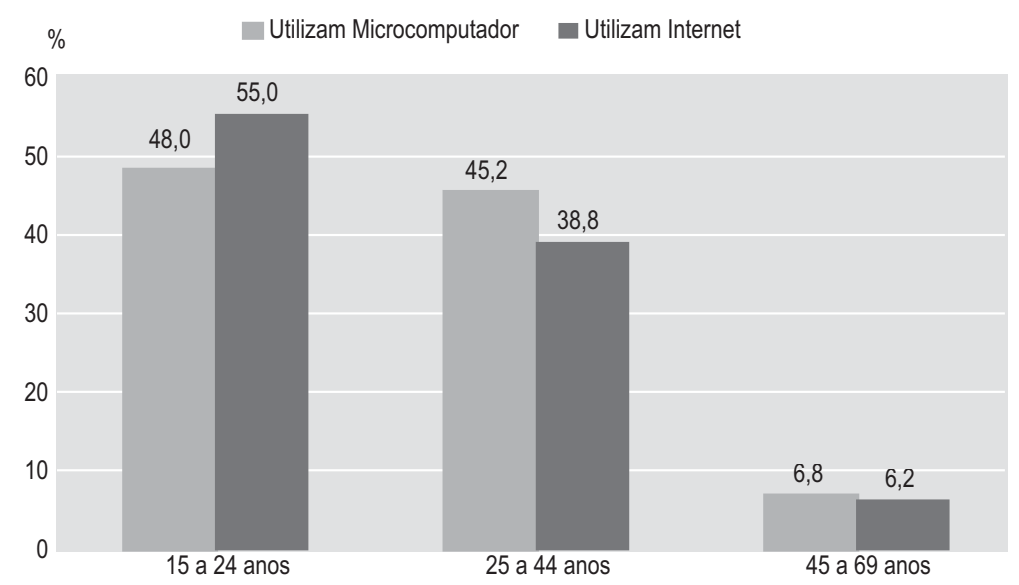

Nota: Os percentuais foram calculados em relação ao próprio grupo.

A distância entre a maior e a menor renda aumenta visivelmente quando passamos dos usuários de computador para os usuários de Internet, o que deve estar relacionado ao custo e à dificuldade de acesso a ela.

\section{GRÁFICO 18}

Renda domiciliar per capita e renda pessoal, segundo o nível de inclusão digital

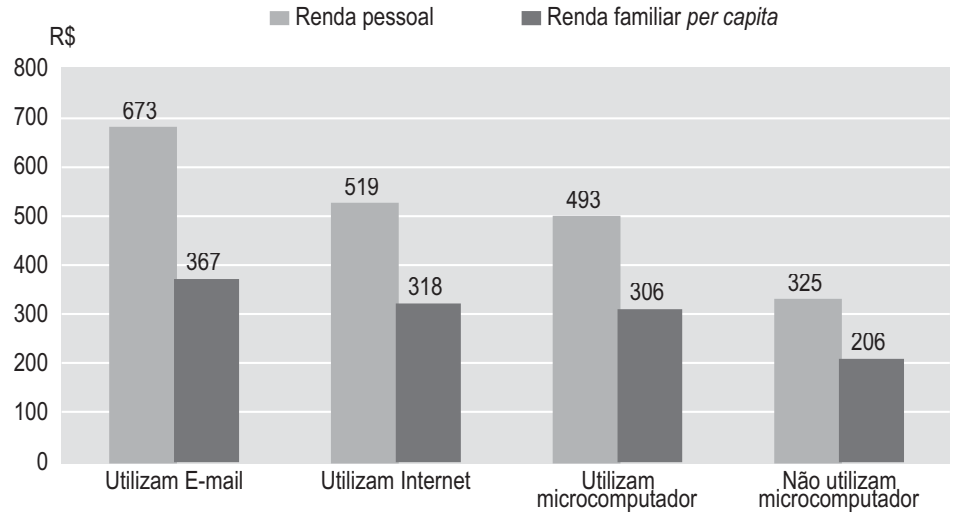

Finalmente, não podemos deixar de indicar um dado que mostra os limites do uso da telemática pelas camadas populares: 
GRÁFICO 19

Percentual de uso de e-mail em relação à utilização de microcomputadores e Internet no total da população das favelas

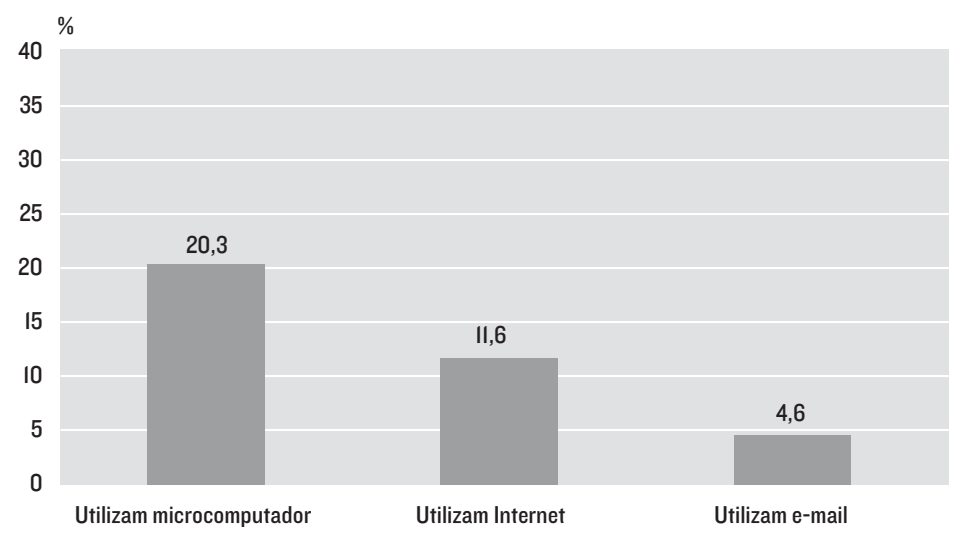

Menos da metade dos usuários da Internet são usuários de e-mail. Trata-se de uma porcentagem muito baixa, produto do contexto social dos habitantes das favelas, onde boa parte da rede social não utiliza Internet, fazendo do e-mail um instrumento menos útil de comunicação.

QUALIDADE DO ACESSO Se os dados anteriores indicam que os caminhos para utilizar o computador e acessar a Internet são múltiplos, todos eles convergem no sentido de indicar as limitações de tempo disponível e da qualidade de acesso do usuário de baixa renda.

Assim, aqueles que possuem computador e acesso à Internet em casa estão limitados pela qualidade (a grande maioria sem acesso à banda larga) e pelo tempo que podem permanecer conectados (já que utilizam acesso discado, que é pago conforme o tempo de permanência na linha). O resultado é uma baixa freqüência de uso.

$\mathrm{O}$ não acesso à Internet rápida com um valor mensal fixo, independentemente do tempo de uso, tem uma dupla conseqüência: a informação demora mais tempo para ser acessada, enquanto o tempo disponível para permanência é menor, já que o usuário paga pelo período em que permanece conectado. Como mostra o Gráfico 20, a intensidade do uso da Internet entre os habitantes das favelas ainda é bastante baixa. No estudo da exclusão digital, portanto, deve-se considerar não somente o número de usuários e não-usuários, mas também a intensidade do uso, tanto na qualidade do acesso (baixa e alta velocidade) como no tempo efetivamente disponível.

Os que têm acesso à informática e ao computador no trabalho podem utilizar esses instrumentos nos limites de suas obrigações e horário de trabalho.

Os que utilizam telecentros dependem da proximidade, de recursos para pagar o serviço e/ou da disponibilidade de computadores no horário de seu interesse.

Aqueles que têm acesso em casa de amigos ou familiares enfrentam igualmente as dificuldades de disponibilidade limitada dos equipamentos. 
GRÁFICO 20

Freqüência do acesso à Internet nas comunidades do município do Rio de Janeiro

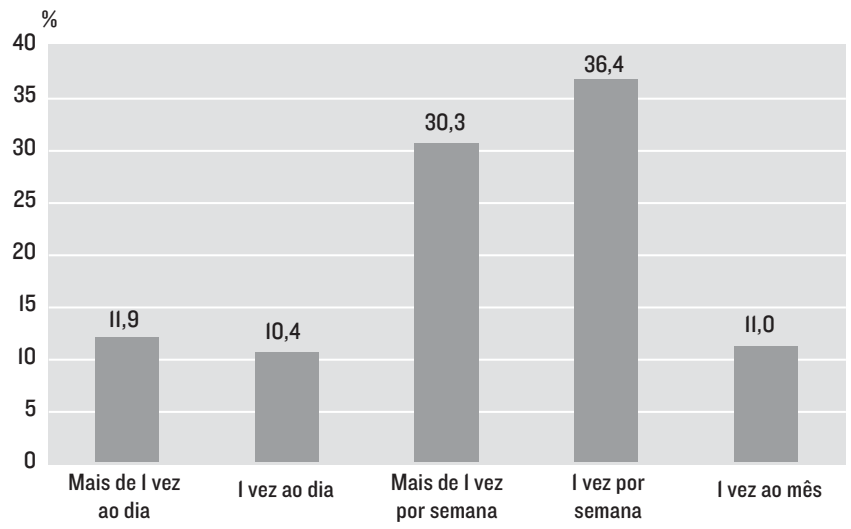

Universo: os que usam a Internet (11,6\% da população).

Finalmente, os usuários das Estações Futuro (telecentros da ONG Viva Rio), com acesso a preços menores, apresentam o mesmo perfil educacional e de renda que o usuário típico da favela. De toda forma, esses locais aumentam a base de usuários e provêm os habitantes da favela, até mesmo os que possuem acesso em casa, com melhor qualidade de serviços, infra-estrutura e apoio.

Embora os comentários anteriores não invalidem a relevância das várias estratégias de universalização de acesso, não pode deixar de ser assinalada a continuidade das desigualdades entre os vários grupos sociais, mesmo entre aqueles que as estatísticas apresentam como tendo acesso à telemática.

CONCLUSÕES: POLítiCAS PÚBLICAS E INCLUSÃo DIGITAL

Levando em consideração os achados da pesquisa e a bibliografia internacional sobre o tema, algumas conclusões sobre os objetivos da universalização do acesso à Internet e sobre a democratização da informação se impõem. Sempre é bom lembrar que, mesmo sublinhando as limitações, não estamos de forma alguma criticando a importância das políticas de universalização de acesso. Pelo contrário, universalizar o conhecimento básico sobre o uso de computadores e Internet é fundamental para limitar o impacto negativo que eles podem trazer para os setores mais pobres. Atualmente, conhecimentos básicos de computação e Internet são crescentemente considerados pré-requisitos de acesso ao emprego.

As políticas de universalização de acesso devem confrontar as complexidades associadas à apropriação efetiva das TICs pelos setores mais pobres da população.

O valor efetivo da informação depende da capacidade dos usuários de interpretá-la. Informação só existe na forma de conhecimento, e conhecimento depende de um longo processo de socialização e de prá- 
ticas que criam a capacidade analítica que transforma bits em conhecimento. Portanto, combater a exclusão digital supõe enfrentar a exclusão escolar.

As políticas de universalização do acesso à Internet nos países em desenvolvimento serão uma quimera se não estiverem associadas a outras políticas sociais, em particular às da formação escolar. Não haverá universalização de acesso às novas tecnologias da informação e da comunicação sem a universalização de outros bens sociais. Nos países em que as taxas de analfabetismo funcional são altíssimas (no Brasil, calcula-se em torno de $30 \%$ ), a luta contra as diversas carências de acesso a serviços públicos (educação, saneamento, segurança, saúde, serviços jurídicos) exige uma visão complexa a respeito da luta contra a exclusão digital. Obviamente, isso não significa que se deva esperar que se chegue a erradicar o analfabetismo para se desenvolver políticas de inclusão digital. Não podemos esquecer que a luta pela inclusão digital é uma luta contra o tempo. As novas tecnologias da informação aumentam a desigualdade social, de forma que a universalização do acesso não é mais do que a luta por um novo nivelamento das condições de acesso ao mercado de trabalho. As exigências da economia e os novos empregos obrigam a convivência de políticas públicas que trabalhem simultaneamente com diferentes setores sociais e ritmos desiguais de universalização de serviços públicos. Não se pode, porém, desconhecer o imbricamento das políticas sociais, e o fato de que o sucesso final depende de um programa integrado de universalização dos vários serviços públicos. No curto prazo, as políticas de inclusão digital, que terão necessariamente um impacto sobre somente uma parte da população mais pobre, devem definir claramente o público-alvo prioritário.

Como foi argumentado anteriormente, é fundamental definir as prioridades do público-alvo. Como a pesquisa indica, a princípio os telecentros em bairros pobres são utilizados pelos setores que já possuem um nível básico de escolaridade e um maior nível de renda. Uma política de universalização do acesso à Internet deve ter como objetivo prioritário a rede escolar, único local onde pode ser efetivamente atingido o conjunto da população. Como a pesquisa também aponta, o local de trabalho é um fator importante de inclusão digital. Desse modo, as políticas deveriam criar incentivos para aumentar o número de empresas usuárias de informática e Internet que oferecessem cursos para todos os seus empregados.

As escolas são instrumentos centrais para socializar as novas gerações na Internet. Isso não implica transformar a telemática num instrumento privilegiado do sistema educativo, nem realizar um investimento exagerado em computadores por escola. Os resultados da pesquisa sobre o impacto do uso da informática e da Internet nas escolas são contraditórios. A adaptação dos professores a esse novo instrumento é um longo processo que não pode ser dissociado da melhoria geral da formação profissional. O desenvolvimento de softwares ade- 
Recebido para publicação

em 08 de janeiro de 2005.

\section{NOVOSESTUDOS}

CEBRAP

$\mathrm{n}-72$, julho 2005

pp. 101-117 quados, a readaptação do sistema pedagógico e o desenvolvimento de disciplinas de ensino crítico do uso da telemática serão, na maioria dos países em desenvolvimento, um processo necessariamente longo. Até lá, o papel dos laboratórios escolares de telemática deve ser o de introduzir os alunos no uso desses instrumentos, capacitando-os para o conhecimento de programas básicos, de forma a facilitar sua futura inserção no mercado de trabalho e motivá-los para o uso de novas tecnologias. Nesses limites, é suficiente oferecer cursos num único ano durante o primeiro segmento do ensino fundamental e, eventualmente, também durante o segundo ciclo.

Uma perspectiva similar deve ser aplicada em relação ao objetivo da democratização da informação. Seu valor efetivo depende da capacidade de interpretação do usuário. Um nível mais alto de escolaridade é fundamental para maximizar o potencial oferecido pela Internet. A promoção de sites com conteúdos específicos para as populações de baixa renda, e em línguas nativas, pode ter um papel importante para compensar as dificuldades de acesso a conteúdos produzidos para públicos de classe média ou com conhecimento de outras línguas. Mas nessa área, apesar do reconhecimento do problema pelos organismos dedicados à inclusão digital, os avanços têm sido muito limitados. $\mathrm{Na}$ atualidade, o financiamento da maioria dos novos conteúdos disponíveis na Internet é feito por capital de risco, o que supõe um retorno do seu investimento. Boa parte do mercado-alvo desses conteúdos é constituída pelas classes médias.

O desenvolvimento de telecentros, isto é, de cabinas de acesso público à Internet, é parte importante em qualquer política de universalização de serviços. Apesar dos esforços das ONGs, as iniciativas têm conseguido um impacto quantitativo praticamente residual, embora cumpram uma importante função de efeito de demonstração e possam ter por vezes um papel importante nas comunidades onde atuam. Mas a universalização do acesso passa fundamentalmente pelas políticas públicas associadas eventualmente ao setor privado e a incentivos ao mercado. O setor privado tem desempenhado um papel importante na criação de telecentros, em geral quando usa equipamento de baixo custo, programas piratas e são administrados pela família proprietária, como indica o exemplo peruano. As políticas públicas, contudo, são fundamentais para atingir uma escala que as iniciativas voluntárias não têm condições de obter. Elas exigem soluções criativas de licitação de serviços para as comunidades mais pobres, com serviços subsidiados, realizados por empresas privadas, associações comunitárias e/ou ONGs.

BERNARDO SORJ é professor titular de Sociologia da Universidade Federal do Rio de Janeiro e diretor do Centro Edelstein de Pesquisas Sociais.

LUÍs EDUARDO GUEDES é pesquisador do Favela, Opinião e Mercado. 